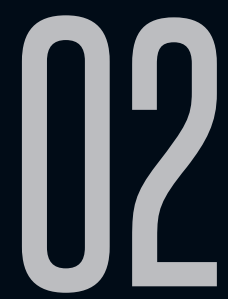

\title{
GUIMARÃES ROSA E A MODALIDADE DO FANTÁSTICO
}

Rubia Alves

Recebido em 20 dez 2016. Rubia Alves - mestranda em Estudos Literários Aprovado em 30 jan 2016. (UNESP-FCLAR), bolsista CAPES.

Contato: rubiaunesp@hotmail.com

Resumo: Ainda que Guimarães Rosa seja um autor conhecido e reconhecido por suas obras vinculadas ao super-regionalismo, é possível notar a influência da literatura fantástica em seus primeiros contos, reunidos e publicados em livro apenas em 2011. Este artigo visa mostrar o momento individual do autor e o momento literário da época em que ele escreveu os contos, considerados imaturos pela crítica. Para isso, analisaremos o conto "Tempo e Destino" e elencaremos aspectos da modalidade do fantástico nele, revelando o que pode ser considerado imitação e o que dessa imitação foi posteriormente assimilado pelo autor para consolidar sua identidade.

Palavras-chave: Guimarães Rosa; Fantástico; Tempo; Destino.

Resumen: A pesar de Guimarães Rosa ser un autor bien conocido y reconocido por su trabajo relacionado con el super-regionalismo, es posible tener en cuenta la influencia de la literatura fantástica en sus primeros cuentos, recogidos y 
publicados en forma de libro sólo en 2011. En este artículo se pretende mostrar el tiempo individual del autor y la literatura de la época en que escribió las historias, considerado por la crítica inmaduras. Para eso, se analiza la historia corta "El tiempo y el destino" y elencaremos aspectos de la modalidad del fantástico, revelando lo que puede considerarse imitación y lo que de esta imitación más tarde fue asimilado por el autor para consolidar su identidad. Palabras-clave: Guimarães Rosa; Fantástico; Tiempo; Destino.

\section{CONSIDERAÇÕES INICIAIS}

Em História concisa da literatura brasileira, Alfredo Bosi (1994) faz um panorama dos obstáculos que o Brasil, país que foi colônia de exploração de Portugal, teve que enfrentar para conseguir dar origem a uma literatura própria. Condicionados pelos pensamentos europeus e pela literatura europeia, os autores brasileiros faziam uma literatura que seguia modelos de escrita baseados na ideologia de países como Portugal, Espanha, Itália e França. A identidade da literatura brasileira, fragmentada como o próprio país, possuía o aspecto de um arquipélago cultural e era construída, lentamente, com base principal na cultura de fora (BOSI, 2006, p.11-12).

O tema da dependência cultural é abordado também pelo teórico Antonio Candido, em A educação pela noite e outros ensaios (2003), no ensaio "Literatura e subdesenvolvimento", que define, metaforicamente, as literaturas latino-americanas como sendo galhos das metropolitanas, pois, ainda que haja certa autonomia, as raízes que sustentam essas literaturas ainda estão fincadas na literatura europeia e são "reflexas" dela. O crítico ressalta que, 
além dessa influência, há outra, mais recente, a influência da literatura norte-americana e é possível perceber implicitamente a dependência cultural mesmo com "resultados originais no plano da realização expressiva" (2003, p.151).

Contrapondo-se a esse processo de europeização cultural, o super-regionalismo configurar-se-ia como uma nova etapa da literatura brasileira, possibilitada pela consciência do subdesenvolvimento e da dependência cultural, consciência esta que foi adquirida pelos escritores pertencentes à etapa denominada regionalista, momento que fez "a literatura, sobretudo o romance e o conto, focalizar a realidade local" (CANDIDO, 2003, p.159-162).

Como um dos representantes do super-regionalismo encontrase o nome de Guimarães Rosa que, segundo Antonio Candido e a crítica posterior, alcançou a transcendência unindo o particular com o universal. A transcendência de Guimarães Rosa pode ser explicada, para Antonio Candido, por meio da "síntese e da fatura" e, para Álvaro Lins, pela imaginação (LEONEL; SEGATTO, 2012, p.104).

Todavia, ainda que Guimarães Rosa seja conhecido e reconhecido por obras de caráter universal e transfigurador, o autor de "livros universalmente significativos" escreveu seus primeiros contos publicados sob influência da literatura europeia e norteamericana, com a influência do escritor Edgar Allan Poe, como mostra Gama-Khalil (2012, p.151) ao comparar o conto "O mistério de Higmore Hall" de Guimarães Rosa com "A queda da casa de Usher" em seu artigo "A literatura fantástica de Guimarães Rosa antes das Primeiras estórias". Luís Eduardo Wexell Machado, em seu artigo "O fantástico em O Mistério de Highmore Hall e Tempo e 
Destino, os primeiros contos de Guimarães Rosa" também defende que os primeiros contos rosianos foram inspirados "na matriz da literatura gótica e fantástica dos séculos XVIII e XIX", com influência de autores como Horace Walpolle, Poe e Lovecraft. Tal matriz seria, posteriormente, "substituída por outra, de caráter regionalista", sem perder "nunca o viço do místico e do inexplicável" (MACHADO, 2011, p.1). Mas, ainda assim, os primeiros contos de Guimarães Rosa são considerados imaturos, pois não apresentam nenhuma transcendência nem podem ser classificados como regionalistas. São intitulados "O mistério de Higmore Hall", "Makiné", "Chronos kai anagke" e "Caçadores de camurça" (LEONEL, 2012, p.105).

Guimarães Rosa, em entrevista concedida a Ascendino Leite (LIMA, 2000, p.61), afirmou que as pessoas deveriam falar sobre aquilo que lhes é mais natural, aquilo com que tem mais familiaridade. Todavia, nos quatro contos citados, o escritor não trata daquilo que lhe está mais próximo, ele segue uma tendência percebida por Osman Lins nos escritores brasileiros:

Os nossos autores começam por tratar não daquilo que lhes é próximo, como a própria vida ou a dos familiares, a sua cidade e as estruturas políticas do país, os acontecimentos contemporâneos, mas, pela imaginação chegam a lugares e tempos distantes. (Apud LEONEL, 2000, p.218)

Naquele momento, havia em Guimarães Rosa mais familiaridade com o distante do que com o local como mostram os seus primeiros contos, diferentemente de Sagarana, obra posterior a esses contos, em que o autor buscou a libertação de qualquer condicionamento literário, como esclarece ele próprio ao falar a respeito do processo de criação dessa obra: 
Rezei, de verdade, para que pudesse esquecerme, por completo, de que algum dia já tivesse existido septos, limitações, tabiques, preconceitos, a respeito de normas, modas, tendências, escolas literárias, doutrinas, conceitos, atualidades e tradições - no tempo e no espaço. Isso, porque: na panela do pobre, tudo é tempero. E, conforme aquele sábio salmão grego de André Maurois: "um rio sem margens é o ideal do peixe" (1984, p.3).

Neste trabalho, estudaremos esses contos não com a leitura mecânica e pouco reflexiva, como a leitura da organizadora do livro Antes das Primeiras estórias (2011). Janaina Senna sugeriu que "o livro serviria para estimular a curiosidade daqueles que gostam de literatura", não merecendo uma introdução crítica feita por um especialista em Guimarães Rosa (GAMA-KHALIL, 2012, p.142-143). Leremos esses contos com um olhar crítico para mostrar a importância deles na formação da identidade do escritor que, embora ainda não tivesse uma voz narrativa própria e se servisse da imitação do estilo de outros escritores e de outras literaturas, mostrou um diferencial em sua escrita e, com a maturidade, conseguiu dialogar com outras influências culturais para formar um sujeito de voz própria capaz de colaborar para o fortalecimento da literatura brasileira e eliminar algumas margens que ainda oprimiam sua escrita.

Para isso, elencaremos alguns aspectos da literatura fantástica no conto "Chronos kai anagke" (Tempo e Destino), considerado imaturo, e mostraremos o que pode ser considerado imitação artística e o que, nesse mesmo conto, são marcas de estilo e autoria, marcas estas que foram consolidadas ao longo da obra rosiana e que constituem parte da identidade temática do autor brasileiro. 


\section{O MOTIVO EM “TEMPO E DESTINO"}

Marisa Martins Gama-Khalil, em seu artigo "A literatura fantástica de Guimarães Rosa antes das Primeiras estórias", diz que o começo do conto "Tempo e Destino" não se assemelha a um conto fantástico, mas, a partir do momento em que o jovem Zviazline começa a vencer as partidas de xadrez, momento esse que coincide com o aparecimento de uma figura estranha, semelhante a Satanás, "toda trama girará em torno de um enredamento que traz em sua arquitetura recursos elaborados da literatura fantástica" (2012, p.152).

O diabo, assim como o vampiro, o fantasma, o lobisomem etc, é uma figura bastante presente na literatura fantástica. Louis Vax, em La séduction de l'étrange (1980), no capítulo três, traduzido por Fábio Lucas Pierini por: "Motivos, temas e esquemas", ao explanar sua concepção do fantástico, aponta a razão desses seres estarem presentes nessa modalidade: eles "possuem por eles mesmos uma virtude de causar angústia" (1980, p.55).

Contudo, é importante ressaltar que, em se tratando de uma narrativa fantástica, é preciso considerá-la em toda a sua amplitude, não a limitando aos seus motivos, visto que uma narrativa pode trazer a figura do monstro e ser totalmente destoante da narrativa fantástica, como fica evidente, por exemplo, no filme Love at first bite (1979), dirigido por Stan Dragoti, em que, embora haja o motivo do vampiro, o filme é, na realidade, uma comédia. A recíproca é verdadeira, como por exemplo, o filme dirigido por Alfred Hitchcock, The birds (1963), em que o motivo dos pássaros não considerado por Vax como um motivo de terror causa no telespectador um medo 
exacerbado, como exemplificou a Profạ. Drạ. Ana Luiza Camarani, na disciplina "A narrativa fantástica", ministrada durante o segundo semestre de 2015, na Universidade Estadual Júlio de Mesquita Filho, em Araraquara.

Vax também rebate a ideia de que os motivos bastam, já que afirma: "O fantasma não é nada por si mesmo. É o contexto que torna precisa sua forma e faz ressoar em nós o tom afetivo que convém. Não é o motivo que faz o fantástico, é o fantástico que se desenvolve a partir do motivo" (1980, p.60-61). O autor exemplifica isso citando a ressurreição de Jesus Cristo, em que o motivo é usado para tratar do tema da esperança; e, em se tratando de um zumbi, é possível abordar o tema do desconcerto e da ameaça. Portanto, é errôneo tentar "determinar a priori a natureza do fantástico", baseando-se na classificação dos motivos. E daí a importância em buscar ligar o motivo ao tema. Como resume Ana Luiza Silva Camarani: “A proposta é que se considere motivo e tema como os dois termos de uma relação dinâmica. (...) A narrativa fantástica deve ser considerada em sua totalidade" (2014, p.45).

Partindo dessa premissa, o aparecimento da figura do Satanás em "Tempo e Destino" não basta para dar ao conto a classificação de fantástico. Contudo, a forma orgânica como essa figura aparece ao longo do conto, sim. Se o processo de antropomorfização de um animal, como o gato, por exemplo, pode carregá-lo de uma "intencionalidade hostil" que o faz parecer um animal noturno e ameaçador, o processo inverso, que seria o de zoomorfização de um personagem, também colabora para carregá-lo de horror (VAX, 1980, p.64-65). 
Inicialmente, os circunstantes do conto "Tempo e Destino" pensam que aquele ser satânico, só um pouco zoomorfizado, é um sujeito de mau gosto que queria zombar deles. Essa seria, portanto, uma explicação racional para o ser estranho que estava ali, e as vitórias do jovem seriam apenas uma coincidência, não tendo, portanto, nenhuma hesitação consistente, ainda, mas que prepara o terreno para a dúvida (MACHADO, 2011, p.9).

Essa criatura que aparece no momento em que Zviazline passa a ganhar as partidas de xadrez vai tomando a fisionomia cada vez mais esdrúxula de um ser totalmente animalizado, ao longo do conto, visto que é descrito como algo que sugere o distanciamento do humano, seja pela descrição das mãos de "dedos finos e compridos como garras", seja pelo riso "escarninho qual cacarejar ou crepitar abafado" (ROSA, 2011), sugerindo uma espécie mais animalesca. O "personagem misterioso dos pesadelos" aparece "envolvido em ampla capa preta, ele se delineava ao bruxoleio baço das tochas, como a silhueta fantástica de um morcego" (2011), sua cara é comparada à cara de um abutre e toda sua fisionomia assemelha-se à de Satanás.

Garras, risada qual cacarejar, semelhança com animais noturnos que despertam o medo como o morcego, tão associado à transmissão da raiva que pode matar; capa preta: cor associada à morte, à noite, ao perigo... Características que dão a essa personagem uma expressão diabólica e animalesca que inspira horror, o mesmo que alguém sentiria se estivesse frente a uma fera. E a caracterização dessa personagem torna-se mais marcante quando, na presença de outra personagem cujas características são totalmente opostas, configura um verdadeiro "pesadelo demoníaco" que agita o "sono de chumbo" do protagonista (ROSA, 2011). 
A figura do diabo nesse conto assemelha-se a da do diabo em $O$ diabo apaixonado, de Jacques Cazotte, na análise feita por Tzvetan Todorov (1981, p.15-16), visto que em ambos ela parece representar um ser de outro mundo e em ambos há características específicas dos humanos, deixando, portanto, a dúvida se tudo não passa de uma ilusão, de um sonho ou se é realmente real.

E se há o questionamento em 0 diabo apaixonado: "Terei dormido?", em "Tempo e Destino" fica a mesma dúvida: "tudo se resumiu para ele num longo pesadelo"? A ambiguidade, "coração do fantástico" para Todorov (1981, p.16), pulsa no conto rosiano analisado e impossibilita que o torneio presenciado por Zviazline seja explicado pelas "leis do mundo familiar".

\section{O UNIVERSO ONÍRICO}

Charles Nodier, precursor das teorias do fantástico, ao traçar as três etapas principais da história da imaginação, pôs em evidência uma característica do fantástico que é de crucial importância: seu vínculo à "representação do real, pois é justamente o desequilíbrio ou a perturbação das leis reconhecidas que determina essa modalidade literária" (Apud CAMARANI, 2014, p.15). Para manter a verossimilhança da narrativa, os escritores valiam-se de "elementos desencadeadores de acontecimentos fantásticos", tais como: o dom visionário, a loucura, as drogas e o sonho (2014, p.15-19).

O universo onírico nos interessa à medida que está presente em "Tempo e Destino" e também em "Conversa de bois", de Sagarana, sendo este super-regional e aquele com influências do fantástico. Em "Conversa de bois", Agenor Soronho e Tiãozinho viajam em um carro de oito bois para levar o corpo do pai já morto do menino que é 
transportado junto a uma carga de rapaduras. A focalização desse conto ora é de Tiãozinho ora é dos bois, que conversam entre si (RIBEIRO, 2015, p.83).

Há um momento em que todas as personagens principais ou dormem ou ficam em estado de sonolência: "O homem está dormindo, o bezerro de homem também está dormindo, dorme caminhando como nós" (ROSA, 1983, p.333) e, nesse momento, os pensamentos dos bois entram em conjunção com o do menino que, triste com a morte do pai, com raiva da mãe e com ódio de Agenor, pensa na falta de justiça e na vontade de vingar-se.

As vozes dos bois se misturando com a voz interior do menino até o momento em que o desejo de justiça presente na criança adquire a força brutal dos animais que, como se raciocinassem, calculam a posição e o grau de vigia tanto de Soronho, quanto de Tiãozinho, para que Soronho morra e o menino não se machuque. “- Namorado, vamos!!... - Tiãozinho deu um grito e um salto para o lado e a vara assobiou no ar." (ROSA, 1983, p.336). E com a ordem dada, os bois correm, Soronho cai do carro e morre. O menino, assustado, diz: "Sonhei... Sonhei e gritei... Nem sei o que me assustou..." (1983, p.337).

O sonho, neste conto, pode ser considerado um elemento desencadeador de algo que está tanto relacionado ao mundo da consciência, quanto ao mundo do pensamento. As leis naturais se misturam com o sobrenatural, com o inexplicável e, assim, possibilitam que a justiça seja feita.

A realização da justiça por meio do extraordinário permeia também outros contos de Guimarães Rosa, tais como "O burrinho 
pedrês", em que a justiça privada de Silvino contra Badú é quebrada e há a justiça divina pela ação do burrinho, e "Corpo fechado", em que um homem fraco e miúdo vence o valentão ao ter o corpo fechado (RIBEIRO, 2015, p.116-118).

Em "Tempo e Destino", o protagonista, homem inexperiente, também vence os outros jogadores, mesmo talvez tendo sido trapaceado. Há, nesse conto, como em outros posteriores do autor, a presença da temática da justiça feita por uma entidade superior que vinga os mais fracos injustiçados. Assim como em "Conversa de bois", "Tempo e Destino" é construído com o elemento desencadeador de acontecimentos fantásticos: as drogas que levam ao sonho/delírio.

Depois de tomar café, Zviazline sente "os efeitos estramonizantes de uma droga criminosamente misturada", efeitos estes que nem ele mesmo conseguiria explicar (ROSA, 2011). Depois disso, entra "num automatismo de sonâmbulo, como se arrastando por chamamento superior e invisível" (2011). O personagem, então, perde a noção do tempo, o que é comum acontecer quando se entra em estado de sonolência, e passa do mundo real para um mundo inexplicável, que poderia existir coerentemente apenas na realidade do sonho. Nisso, o Tempo e o Destino jogam xadrez e ensinam ao jovem o mito de Prometeu, a História, como a vida oferece combinações e que o bem e o mal são necessários a ela. Há uma confusão entre o que é real e o que não é. Sonho e realidade fundem-se e confundem-se, quebrando assim a "conveniência racional" até que aquela confusão semelhante a "um filme sobrenatural" vai se desfazendo por meio de uma técnica utilizada também por Machado de Assis no delírio de Memórias póstumas de 
Brás Cubas (1998), e o personagem de "Tempo e Destino" sente-se como "um grande besouro a gravitar em torno de dois sóis de fogo, enormes e coruscantes" os quais se reduzem até transformarem-se em "tremeluzir de vagalumes distantes" (2011, p.68).

A figura do vagalume também é utilizada, posteriormente, por Guimarães Rosa, no conto "As margens da alegria", em Primeiras estórias (1988). Em ambos os contos é possível associar o vagalume ao significado atribuído por Rosiane Cristina Runho, em sua tese de doutorado A memória e o olhar em contos de Primeiras estórias, ou seja, à luz e, portanto, ao entendimento. Luz e conhecimento são "elementos que permeiam algumas das ideias de Platão" (2001, p.7) e que representam a ascensão das ideias que levam ao conhecimento.

O fantástico está atrelado ao gótico que, para ser compreendido, exige vê-lo sob a perspectiva das razões históricas relevantes para o seu surgimento. O gótico é produto do Século das Luzes, momento histórico em que o saber estava fortemente atrelado ao conhecimento científico e suspeitava dos acontecimentos aparentemente irracionais ou que fugiam da lei da natureza. A razão era neste período tão inquestionável como a superstição e a fé no período anterior a ela. Mas o gótico, por meio da dúvida, usaria de acontecimentos extraordinários que se oporiam às leis da natureza visando alcançar "um ceticismo radical" (LÉVY, 1980, p.41).

Tais acontecimentos seriam admissíveis por estarem em consonância com superstições primitivas e com elementos que guardavam algo de catolicismo. Há o resgate da época em que havia uma crença marcante em coisas ocultas e sobrenaturais, consequência de "uma sensibilidade mais primitiva". O gótico só 
poderia surgir em um momento posterior às épocas em que a vida era mitificada e que era totalmente desmitificada. Walpole, com seu primeiro conto gótico, baseado nessa premissa, teria possibilitado o surgimento de outros textos góticos, cujo direcionamento "conduz à exploração do irracional sob o controle da razão e fundamenta a escritura sobre um conflito fecundo entre o familiar e o estranho" (LÉVY, 1980, p.41-42).

Procedente do gótico, o fantástico moderno manteria o ceticismo radical liberando "os instintos que haviam dedicado séculos a domesticar" ao mesmo tempo em que preservaria "a mesma atenção ao real" (LÉVY, 1980, p.43).

A disputa de xadrez em "Tempo e Destino" pode ser lida como uma metáfora sobre a disputa e a busca da verdade. Como a própria personagem, conhecida pelos que a julgam boa como providência e como destino; pelos que a temem, diz: aquela disputa presenciada por Zviazline é uma iniciação para o conhecimento da verdade, por meio do xadrez, "único tarot absoluto, chave de todo simbolismo!" (ROSA, 2011, p.64).

\section{O FAMILIAR, O ESTRANHO E A VIAGEM}

Em "A Vênus de Ille", de Perser Mérimée, há o viajante que chega a um lugar e entra em contato com o desconhecido. "A outra volta do parafuso", de Henry James, também traz o tema de uma viajante adentrando em um espaço desconhecido. É frequente em histórias de terror aparecer a figura do viajante, pois, na modalidade do fantástico, há a rejeição do mais familiar e o desejo do estranho e uma das formas de romper com o familiar é deslocar a personagem para um espaço desconhecido para ela. 
Em "Tempo e Destino", o protagonista também está deslocado de seu espaço familiar e adentra em outro, estranho a ele, para vivenciar algo diferente daquilo que lhe é natural. Ele sai da sua "pequenina cidade natal, no coração da Ucrânia, levando um mundo de esperanças e ilusões" (ROSA, 2011, p.56) e vai para

a cidade de K..., importante estação balneária do sul da Alemanha, onde borborinhava, naquele fim de verão, uma mistura heterogênea e cosmopolita [...] tipos de nacionalidade dúbia, espécimes de fauna nômade nos hotéis, cassinos e transatlânticos (2011, p.55-56).

De maneira análoga às vivências experimentadas por personagens viajantes da modalidade do fantástico.

Guimarães Rosa explorou muito o tema da viagem em suas obras, pois para ele, que tinha que fazer várias viagens por conta da profissão, a "viagem para fora do espaço de origem é também viagem para dentro, para Minas, para o sertão que representa o Brasil em suas virtudes e mazelas e o homem em sua universalidade" (LEONEL, 2002, p.90). Em Grande Sertão: Veredas, o personagem Riobaldo atravessa lugares que convergem ao espaço que não tem limites nem fronteiras, vão de encontro ao espaço ilimitado do mundo. A paisagem das veredas encontra-se por toda a extensão do percurso como um elemento que unifica e dá sentido à viagem esférica de Riobaldo. O viver e o viajar confundem-se, a viagem torna-se a própria existência e é durante esse percurso que o Bem e o Mal são aprendidos por Riobaldo. A viagem é redonda, é a travessia das coisas "[...] é vivência e descoberta do mundo e de nós mesmos" (NUNES, 1969, p.175). 
Em Sagarana, no conto "O burrinho pedrês", há, durante a viagem, a modificação do destino dos viajantes e se percebe, ao longo de todo o conto, os movimentos de "ida-e-volta". Em "A volta do marido pródigo", o marido vende a mulher e viaja para a cidade grande onde conhece outros prazeres, contudo, há a mudança do personagem Lalino Salantiel, o marido, que volta para a mulher após aprender o valor que têm o lugar e as pessoas com que ele morava.

Em "A terceira margem do rio", o pai faz uma viagem à mercê do barco e do rio, por onde fica sozinho com sua loucura (NUNES, 1969, p.178). Segundo Ana Paula Pacheco, a partida do pai ao rio possui estreita relação com o encontro da morte, mesmo que seja num sentido simbólico (2006, p.148). O pai percorre um caminho de sentido oposto à renovação, a viagem que ele faz é uma espécie de retorno ao animalesco, à categoria de bicho. Ficar numa terceira margem, sem comer nem falar com ninguém é, de certa maneira, "abandonar a cultura do cozido" (2006, p.151).

Em "As margens da alegria", a viagem possibilita o amadurecimento da criança, pois ela tem que romper com alguns laços externos para se desenvolver, pois, embora o Menino se encontre numa atmosfera familiar, os pais não estão junto dele (PACHECO, 2006, p.32). Nesse conto, a paisagem se transforma conforme a perspectiva do Menino, protagonista da história, muda.

A viagem, entendida como um deslocar-se, não é apenas uma busca de respostas, é um processo contínuo de perguntas, de questionamentos sobre paisagens e sobre seres. A literatura fantástica é também, de certa maneira, um deslocar de pensamentos e conceitos, que se movem para revelar a interioridade de sujeitos e simbologias coletivas. 


\section{CONSIDERAÇÕES FINAIS}

Chegamos tarde e tudo já foi dito (LA BRUYÈRE) ou

Chegamos cedo, nada foi dito (LAUTRÈAMONT).

Considerando que a produção literária não é um processo isolado, é um processo de continuidade que prevê diálogos com obras anteriores, seja por meio de retomadas, empréstimos e/ou trocas e considerando a presença da imitação na prática intertextual ressignificada a partir do final do século XIX, sem mais servir apenas de modelo canônico para obras literárias (ALVES, 2012, p.79), foi possível mostrar que Guimarães Rosa recuperou alguns aspectos da narrativa do fantástico por meio de motivos e temas.

Neste trabalho, mostramos um pouco da modalidade fantástica e um pouco da obra rosiana na tentativa, não de classificar o conto "Tempo e Destino" como pertencente ao fantástico, mas sim, de revelar a presença, ainda que dissolvida e ressignificada, do legado deixado pelos escritores tão conhecidos por terem escrito "contos de terror".

Nesse sentido tentamos demonstrar que Guimarães Rosa dialogou de certa maneira com uma corrente de literatura estrangeira posterior ao momento de escrita dele, seja aproveitando motivos como o da viagem e o da figura demoníaca, seja abordando o universo onírico e o das drogas, seja trazendo à tona a discussão em torno do real e do sobrenatural, seja rejeitando o familiar e entrando em contato com o estranho, seja criando certa ambiguidade, utilizando a modalização para inserir a dúvida. 
Pertencente a um sistema cultural recordado pela ficção regionalista, Guimarães Rosa mostrou que esse período não é marcado pela desvinculação do modernismo, mas ao aproveitamento das conquistas do período que antecederam sua escrita, seja pelo aproveitamento da linguagem, da desmetrificação, da valorização do coloquial, da ironia, do prosaico etc, conquistas que significaram uma preparação ao desenvolvimento artístico de muitos escritores brasileiros (BOSI, 1936, p.411).

E é possível acrescentar que o escritor brasileiro que alegava: "Estudava línguas para não me afogar completamente na vida interior" (Apud LEONEL, 2002, p.88) demonstra ter aproveitado os recursos da intertextualidade revisitada por Oswald de Andrade que defendia a Antropofagia cultural no que tange "o desejo do Outro, a abertura e a receptividade para o alheio, desembocando na devoração e na absorção da alteridade" (PERRONE-MOISÉS, 1990, p.95).

Assim sendo, o estudo do conto "Tempo e Destino" sobre o viés da narrativa fantástica viabilizou revisitar outros textos e ampliar as possibilidades de leitura. Como uma das características elencada pelos críticos literários de Guimarães Rosa é a imaginação, cabe aqui citarmos Schneider que diz: “A própria memória é uma forma da imaginação, uma ficção que reescreve os vestígios deixados, enquanto a imaginação, por mais criativa que seja, procede da lembrança daquilo que não se produziu" (1990, p.19). O conto "Tempo e Destino" traz consigo marcas de outros textos, imprevisíveis e inevitáveis, que nos desencorajam a pensá-lo ignorando autores da literatura fantástica. Esse conto traz consigo também novos sentidos, que estão presentes em outras narrativas de sua autoria, tão significativos para a consolidação da literatura brasileira. 


\section{REFERÊNCIAS}

ALVES, Elaine Cunha de Oliveira (2012). Diálogos poéticos de um legionário: intertextualidade nas canções de Renato Russo. Tese (mestrado). Araraquara: Faculdade de Ciências e Letras da Universidade Estadual Paulista "Júlio de Mesquita Filho".

ASSIS, Machado de (1998). Memórias póstumas de Brás Cubas. São Paulo: Coleção Prestígio.

BOSI, Alfredo (1994). História concisa da literatura brasileira. São Paulo: Cultrix. CAMARANI, Ana Luiza Silva (2014). A literatura fantástica: caminhos teóricos. São Paulo: Cultura Acadêmica.

CANDIDO, Antonio (2003). A educação pela noite \& outros ensaios. São Paulo: Ática.

DRAGOTI, Stan (Diretor) (1979). Love at first bite [Filme]. USA: AIP. GAMA-KHALIL, Marisa (2012). "A literatura fantástica de Guimarães Rosa antes das Primeiras estórias". Olho d'água, 4(1). In http://www. olhodagua.ibilce.unesp.br/index.php/Olhodagua/article/view/111 Acesso em 23.Nov.2015.

GUIMARÃES, Rosa (1988). Primeiras Estórias. Rio de Janeiro: Nova Fronteira.

HITCHCOCK, Alfred (Diretor) (1963). The birds [Filme]. USA: Universal Pictures.

LEONEL, Maria Célia (2000). Guimarães Rosa: Magma e gênese da obra. São Paulo: Editora UNESP. (2002). "Viagens rosianas". In: MARCHEZAN, Luiz Gonzaga; TELAROLLI, Sylvia (Orgs.). Cenas literárias: a narrativa em foco. Araraquara: UNESP/FCLAR. p.87-112.

. SEGATTO, José Antonio (2012). Fiç̧ão e ensaio: literatura e história no Brasil. São Carlos: EdUSFSCAR. p.151-162.

LÉVY, Maurice (1980). "Gothique et fantastique". Europe - Revue Littéraire Mensuelle. Paris: Europe et les Editeurs Français Réunis, p.41-48.

LIMA, Sônia Maria van Dijck (Org.) (2000). Ascendino Leite entrevista Guimarães Rosa. 2.ed. Revista. João Pessoa: Editora Universitária/UFPB. 
MACHADO, Luís Eduardo Wexell (2009). "O fantástico em O Mistério de Highmore Hall e Tempo e Destino, os primeiros contos de Guimarães Rosa". FronteiraZ, 3. In http://revistas.pucsp.br/index.php/fronteiraz/article/view/12556 Acesso em 23.Nov.2015.

NUNES, Benedito (1969). O dorso do tigre. São Paulo: Perspectiva.

PACHECO, Ana Paula (2006). Lugar do mito: narrativa e processo social nas Primeiras estórias de Guimarães Rosa. São Paulo: Nankin.

PERRONE-MOISÉS, Leyla (1990). Flores da escrivaninha. São Paulo: Cia das Letras. RIBEIRO, Gustavo de Mello Sá Carvalho (2015). Relatório de atividades desenvolvidas. [Texto não publicado]

ROSA, João Guimarães (1984). Sagarana. Rio de Janeiro: Record/Altaya. . (2011). Antes das primeiras estórias. Rio de Janeiro: Ed. Nova Fronteira. RUNHO, Rosiane Cristina (2001). A memória e o olhar em contos de Primeiras estórias. Tese (doutorado). Araraquara: Faculdade de Ciências e Letras da Universidade Estadual Paulista "Júlio de Mesquita Filho".

SCHNEIDER, Michel (1990). Ladrões de palavras: ensaio sobre o plágio, a psicanálise e o pensamento. Tradução de Luiz Fernando P. N. Franco. Campinas: Editora da Unicamp.

TODOROV, Tzvetan (1981). Introdução à literatura fantástica. São Paulo: Ed. Perspectiva.

VAX, Louis (1980). "Thèmes, motifs et schèmes". In: La séduction de l'étrange. Paris: Presses Universitaires de France, p.53- 88. 